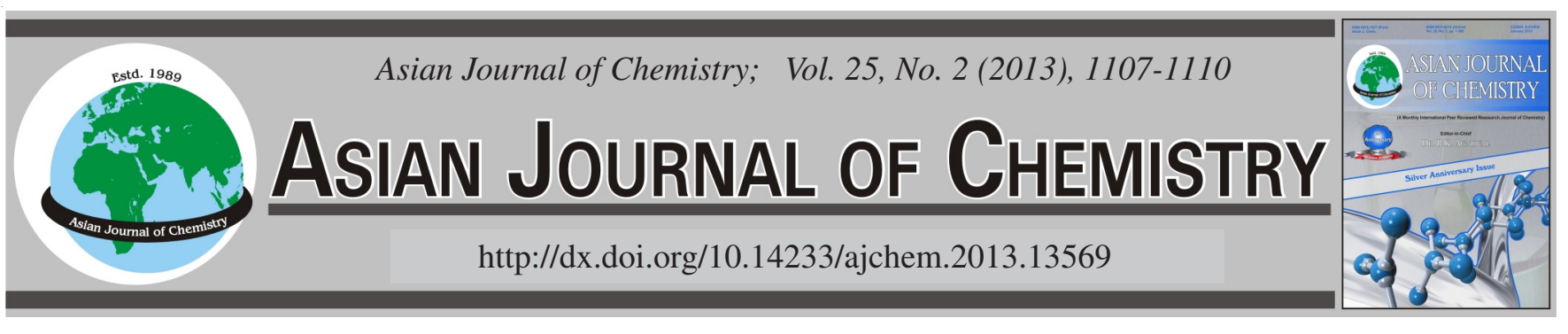

\title{
Investigation of the Effects of Alkaline Treatment on the Properties of Poly(3,4-ethylenedioxythiophene):Poly(4-styrenesulfonate) Films
}

\author{
JiAo Li", HuA Zhang, Juncheng Liu and Hui Qi
}

School of Materials Science and Engineering, Shandong University of Technology, Zibo 255049, Shandong Province, P.R. China

*Corresponding author: E-mail: zbjli2012@163.com

(Received: 8 February 2012;

Accepted: 31 August 2012)

AJC-12054

\begin{abstract}
In this article, the influence of sodium hydroxide treatment on the properties of poly(3,4-ethylenedioxythiophene):poly(4-styrenesulfonate) (PEDOT:PSS) films has been investigated. We have also examined the performance of organic solar cells with the un-doped and $\mathrm{NaOH}-$ doped PEDOT:PSS layer. Results show that the acidity of PEDOT:PSS solution can be remarkably reduced by adding the $\mathrm{NaOH}$ solution with the optimal doping concentration $(\leq 0.43 \mathrm{wt} \%)$, while the $\mathrm{NaOH}$-doped PEDOT:PSS film shows an improved optical transmission and unchanged conductivity. However, compared with the pristine organic solar cell without adding $\mathrm{NaOH}$ to the whole-extraction layer, the $\mathrm{NaOH}$-doped organic solar cell shows a slightly degraded in the power conversion efficiency (from 2.12 to $2.01 \%$ ), which has been attributed to the decreased $\mathrm{V}_{\mathrm{oc}}$ and fill factor of the devices after the addition of $\mathrm{NaOH}$.
\end{abstract}

Key Words: Poly(3,4-ethylenedioxythiophene):poly(4-styrenesulfonate) film, Sodium hydroxide, Property, Organic solar cells.

ᄂ - - - - - - - - - - - - - - - - - - - - - - - - -

\section{INTRODUCTION}

Recently, poly(3,4-ethylenedioxythiophene) (PEDOT) doped with poly(4-styrenesulfonate) (PSS) has attracted much attention due to their exceptional advantage of high transparency in the visible range, excellent thermal stability and aqueous solution processibility ${ }^{1,2}$. With all these properties, PEDOT:PSS is now widely used in optoelectronic devices. For example, it can be used as an efficient hole-extracting layer between the indium tin oxide (ITO) and active layers in organic solar cells $(\mathrm{OSCs})^{3-5}$. However, it is found that the ITO/PEDOT:PSS interface is not stable due to the etching of ITO by the strong acidic nature of PSS $^{6}$. The degraded interface can act as a defect site and lead to deterioration of the device performance ${ }^{7,8}$.

Several attempts have been done to find the replacement of PEDOT:PSS by a more suitable material, such as acidcarbon nanotubes ${ }^{9}, \mathrm{NiO}^{10}$ and SWCNTs-porphyrin ${ }^{11}$. However, the performances of organic solar cells with these replacements are lower than the device with the hole-extraction layer of PEDOT:PSS. According to the acid-base theory, the acidity of a solution can be neutralized by adding the alkaline solution. To the best of our knowledge, the use of an alkaline solution to reduce the acidity of PEDOT:PSS has hardly been reported, thus this could be an alternative to achieve better film properties.

In this study, the PEDOT:PSS doped with $\mathrm{NaOH}$ transparent conducting films will be fabricated on quartz substrates by spin-coating method. We will investigate the influence of $\mathrm{NaOH}$ treatment on the properties of PEDOT:PSS films. Moreover, we will study the performance of polymer solar cells with the un-doped and doped PEDOT:PSS layer.

EXPERIMENTAL

Poly $(3,4$-ethylenedioxy thiophene):poly(4-styrenesulfonate) (PEDOT:PSS) aqueous solution (1.3 wt \% dispersed in $\mathrm{H}_{2} \mathrm{O}$ ) from Aldrich (as supplied) was filtered with a 0.45 $\mu \mathrm{m}$ polyvinyl difluoride (PVDF) syringe filter. Sodium hydroxide (analytical grade), used as a dopant, was purchased from Aldrich (as supplied). Other reagents and solvents were of analytical grade.

All the quartz substrates $(20 \mathrm{~mm} \times 20 \mathrm{~mm})$ were ultrasonically cleaned with a series of organic solvents (ethanol, methanol and acetone), then rinsed in an ultrasonic bath with deionized water and dried in a vacuum oven. Residual organic contaminations were subsequently removed by exposing to a UV-ozone lamp for $0.5 \mathrm{~h}$. Prior to spin-coating, a certain mass ratio of $\mathrm{NaOH}$ and PEDOT:PSS solution was prepared. The PEDOT:PSS and $\mathrm{NaOH}$-doped PEDOT:PSS films with a thickness of 95-100 nm, as determined with scanning electron microscopy, were fabricated on transparent quartz substrates by spin-coating method. The spin coating procedure included $20 \mathrm{~s}$ of $2000 \mathrm{rpm}$ followed by $30 \mathrm{~s}$ of $5000 \mathrm{rmp}$. Then these films were dried at $110{ }^{\circ} \mathrm{C}$ for $15 \mathrm{~min}$ in the vacuum oven before any further characterization. 
The devices in this work were fabricated using indium tin oxide (ITO) coated glass substrates $(<10 \Omega / ? ?)$. The treatment process of indium tin oxide substrate was same as the quartz substrate and solution of $\mathrm{NaOH}$ and PEDOT:PSS was spinning coated on top of the indium tin oxide surface to form a buffer layer $(90-100 \mathrm{~nm})$ before drying the substrates at $110^{\circ} \mathrm{C}$ in an oven for $15 \mathrm{~min}$. The $\mathrm{P}_{3} \mathrm{HT}$ : PCBM was dissolved in dichlorobenzene at a weight ratio of 1:0.8 and stirred for more than $72 \mathrm{~h}$ in the glove box before spin casting to form the blend layer. Finally, an Al electrode of about $100 \mathrm{~nm}$ in thickness was deposited by thermal evaporation at a pressure of $2.4 \times 10^{-4} \mathrm{~Pa}$ through a shadow mask. The basic structure of the organic photovoltaics (OPV) devices is shown in Fig. 1.

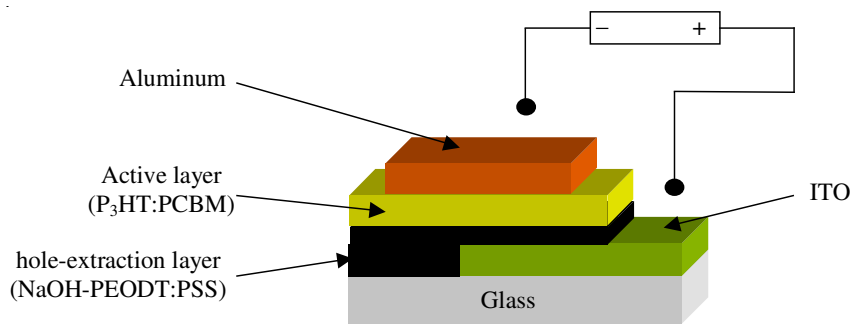

Fig. 1. Schematic device structure for organic solar cells doped with $\mathrm{NaOH}$

The $\mathrm{pH}$ of the solution was measured by the PHS-3C $\mathrm{pH}$ meter. The conductivity of the films was measured by the fourpoint probe technique with a Keithley 2400 Source Meter. The optical property of the composite films was characterized with a TU-1901 Dual-beam UV-Visible spectrophotometer. Current density-voltage (I-V) characteristics of the organic photovoltaics cells were measured using a computer-controlled Keithley 2400 Source Meter under a simulated light intensity of 100 $\mathrm{mW} / \mathrm{cm}^{2}$ (AM $1.5 \mathrm{G}$ ) calibrated by an optical power meter from a halogen lamp. The power conversion efficiency (PCE) was calculated from the I-V characteristics. The devices were tested in the air without encapsulation and all the measurements were performed at room temperature.

\section{RESULTS AND DISCUSSION}

Effects of $\mathrm{NaOH}$ treatment on the pH of PEDOT:PSS solutions: As is shown in Fig. 2, the $\mathrm{pH}$ of commercially available PEDOT:PSS solution is about 1.51 and there is a two-stage increase in the $\mathrm{pH}$ of PEDOT:PSS solution with increasing the $\mathrm{NaOH}$ doping concentration. Firstly, there is a slowly increase of the $\mathrm{pH}$ with increasing frequency from 0 to 0.40 wt $\%$, then the $\mathrm{pH}$ increases drastically when $\mathrm{NaOH}$ doping concentration increases from 0.40 to $0.47 \mathrm{wt} \%$. When the $\mathrm{NaOH}$ doping concentration is about $0.43 \mathrm{wt} \%$, the $\mathrm{pH}$ of composite solution is near neutral (6.94). This indicates that the acidity of PEDOT:PSS solution can be remarkably reduced by $\mathrm{NaOH}$ fillings.

Effects of alkali treatment on the electrical property of PEDOT:PSS films: The plots of the electrical conductivity as a function of weight fraction of $\mathrm{NaOH}$ at room temperature are shown in Fig. 3. Upon increasing the $\mathrm{NaOH}$ doping concentration, the conductivity of doped films initially keeps constantly and then decreases. When $\mathrm{NaOH}$ content reaches about 0.47 wt $\%$, the conductivity of doped film is about $0.12 \mathrm{~S} / \mathrm{cm}$, less about $57.1 \%$ than that of pure PEDOT:PSS film $(0.28 \mathrm{~S} / \mathrm{cm})$.

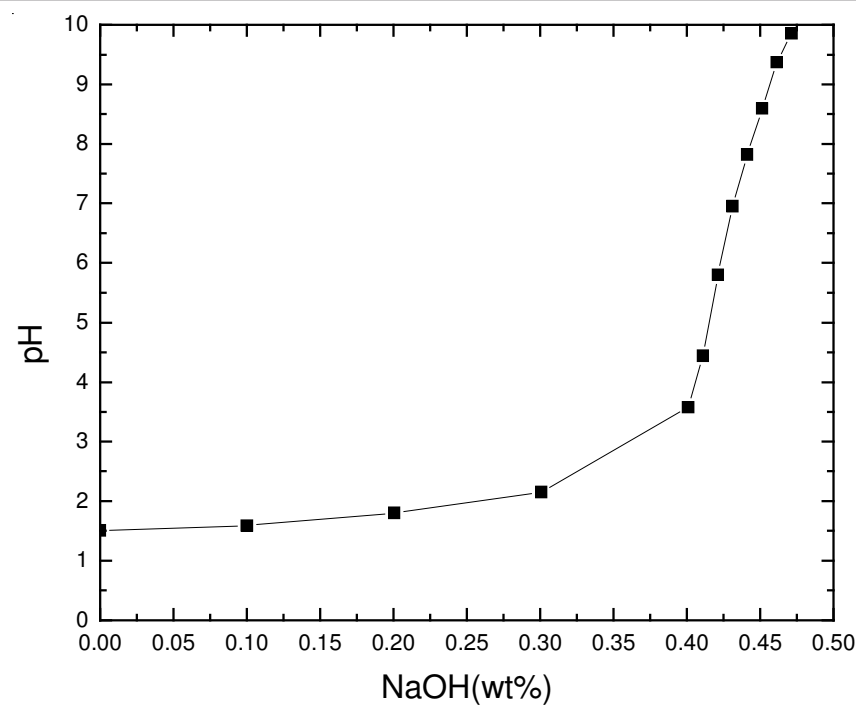

Fig. 2. pH of PEDOT:PSS solutions with different content of $\mathrm{NaOH}$

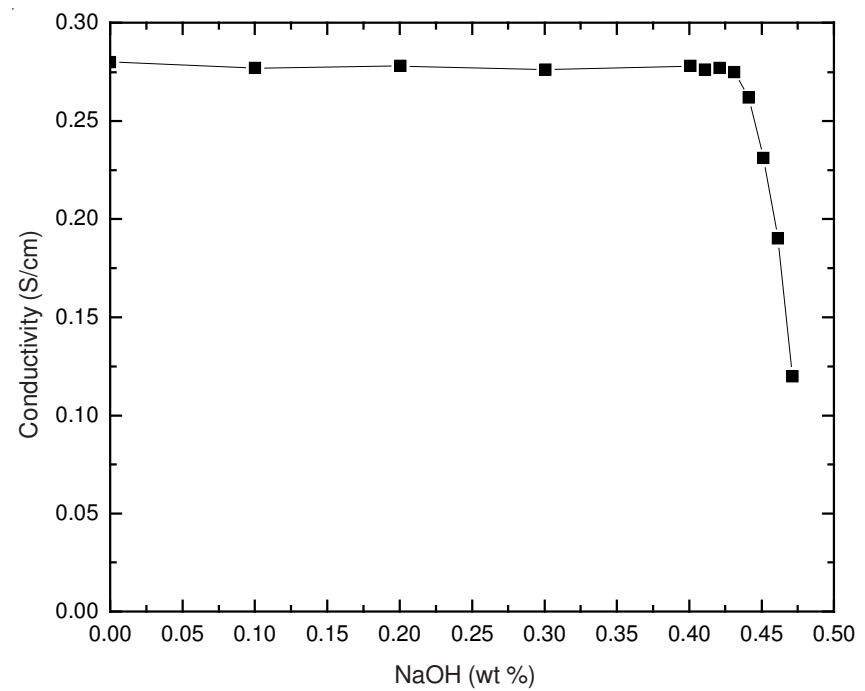

Fig. 3. Electrical conductivity of PEDOT:PSS films with different content of $\mathrm{NaOH}$

This result indicates that the addition of $\mathrm{NaOH}$ up to 0.43 wt $\%$ has no effect on the conductivity of doped films, but to further increase of $\mathrm{NaOH}$ content in the blend solution results in the alkalinity of PEDOT:PSS solution. The $p$-doped PEDOT chain may be de-doped in basic environments. It will cause changes in their electronic states, which lead to the film conductivity decreases ${ }^{12,13}$.

Effects of $\mathrm{NaOH}$ treatment on the optical property of PEDOT:PSS films: When PEDOT:PSS is applied in organic solar cell devices, it's always important to keep its transmittance high. This is because the better optical property of PEDOT:PSS layer is conducive to increase the absorption of light and the generation of excitons within the active region of the solar cell, which is of great benefit to improve the organic solar cells performance ${ }^{14,15}$. Fig. 4 showed that the optical transmittance of PEDOT:PSS films modified with different $\mathrm{NaOH}$ doping concentration are slightly increased up in the wavelength range from 600 to $800 \mathrm{~nm}$, which corresponds to the power density of ambient sunlight on the earth's surface ${ }^{14}$. In particular, the pronounced increase is observed in the wavelengths 


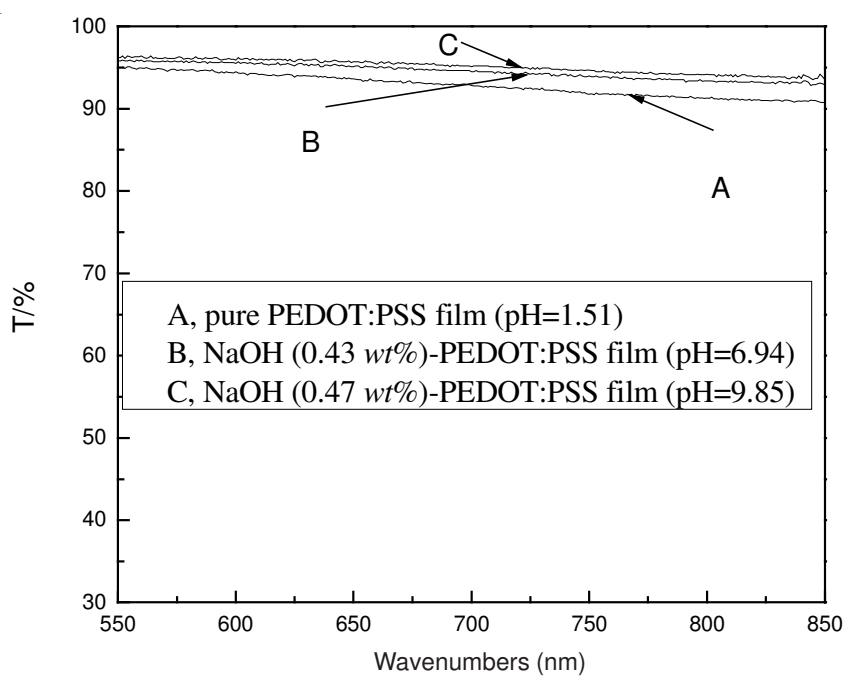

Fig. 4. Optical transmittance of PEDOT:PSS films with different content of $\mathrm{NaOH}$

between 700 and $800 \mathrm{~nm}$. This indicates that the added $\mathrm{NaOH}$ might influence the interaction environment between PEDOT and PSS $^{-}$.

Effects of $\mathrm{NaOH}$ treatment on the performance of organic solar cells: Fig. 5 shows the current density-voltage curves of photovoltaic cells with un-doped and doped PEDOT:PSS films as the hole-extraction layer of devices. The detailed parameters of devices are summarized in Table-1. As shown in Table-1, there is an obviously decrease in the open circuit voltage $\left(\mathrm{V}_{\mathrm{oc}}\right)$ with the increase in the $\mathrm{NaOH}$ amount. $\mathrm{V}_{\text {oc }}$ of the organic photovoltaic cell is limited by the work function of the electrodes or the buffer layers, i.e., it is determined by the work function of PEDOT:PSS films ${ }^{16,17}$. For this reason, it can be concluded that a decrease in $\mathrm{V}_{\mathrm{oc}}$ with the addition of $\mathrm{NaOH}$ is mainly a result of deterioration in modifying the work function of the PEDOT:PSS film. Meanwhile, it was reported that the content of $\mathrm{PSS}^{-}$of PEDOT:PSS films played an important role in the work function of the PEDOT:PSS film ${ }^{18}$. Here, the addition of $\mathrm{NaOH}$ into PEDOT:PSS may be brought more effect

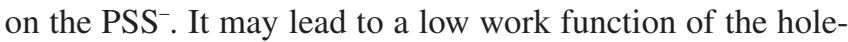
extraction layer compared to un-doped PEDOT:PSS film and has an effect on $\mathrm{V}_{\mathrm{oc}}$ of the photovoltaic cell. However, this is still an assumption and needs to be further studied.

Table-1 also shows the increase in the short circuit current ( $\left.\mathrm{I}_{\mathrm{sc}}\right)$ from about $8.82 \mathrm{~mA} / \mathrm{cm}^{2}$ of the reference device $\mathrm{A}(0$ wt $\%)$ to $9.06 \mathrm{~mA} / \mathrm{cm}^{2}$ of the device $\mathrm{B}(0.43 \mathrm{wt} \%)$ and after that the $\mathrm{I}_{\mathrm{sc}}$ decreases to become $5.72 \mathrm{~mA} / \mathrm{cm}^{2}$ of the device $\mathrm{C}$ $(0.47 \mathrm{wt} \%)$. Since these devices are fabricated with the same materials and the same procedure and the only difference is the hole-extraction layer, the increased current is unlikely on account of other reasons. Moreover, compared with un-doped films, doped films ( $\leq 0.43 \mathrm{wt} \%)$ show a constant conductivity and a slight increase optical transmittance in the wavelength

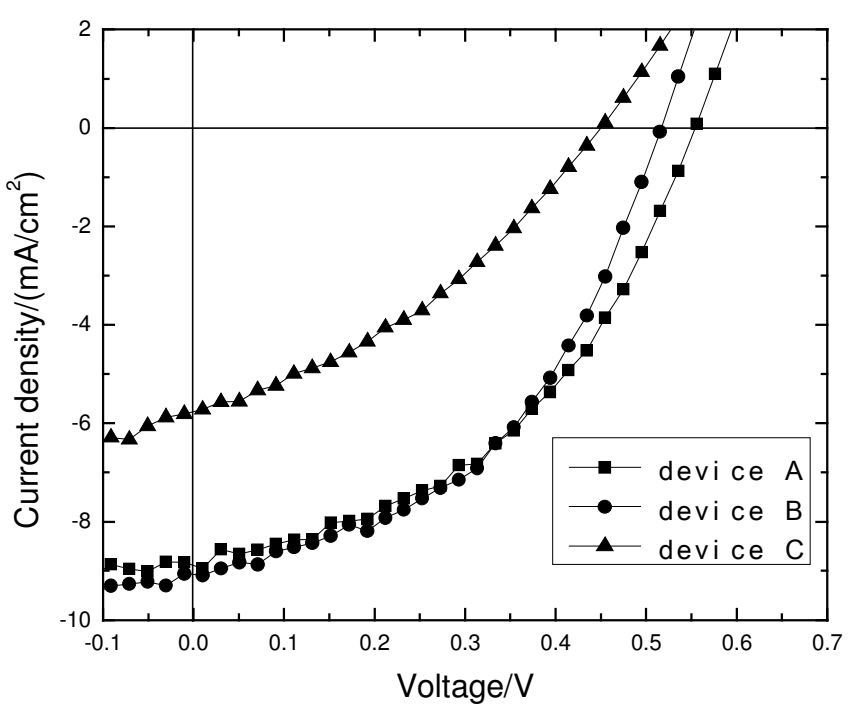

Fig. 5. The I-V characteristics of devices with different content of $\mathrm{NaOH}$; Device A: pristine PEDOT: PSS film; Device B: $\mathrm{NaOH}(0.43 \mathrm{wt} \%)$ PEDOT: PSS film; Device C: $\mathrm{NaOH}(0.47 \mathrm{wt} \%)$-PEDOT: PSS film

range from 600 to $800 \mathrm{~nm}$ (Figs. 3 and 4). Therefore, the increased current is mainly due to the high optical transmittance of the hole-extraction layers, leading to a higher photon absorption yield and the charge carrier transport yield within the active region of the device ${ }^{14}$. The more hole-carriers in the $\mathrm{P}_{3} \mathrm{HT} / \mathrm{PCBM}$ active layer move into the anode through the PEDOT:PSS film. While the decrease in $\mathrm{I}_{\mathrm{sc}}$ after adding more amounts of $\mathrm{NaOH}$ may be due to the decrease of the conductivity of doped films $(\geq 0.43 \mathrm{wt} \%)$, which has effects on the series resistance of organic photovoltaic cell.

The change of $\mathrm{V}_{\mathrm{oc}}$ and $\mathrm{I}_{\mathrm{sc}}$ with increased $\mathrm{NaOH}$ content is also responsible for the fill factor (FF) and power conversion efficiency of organic solar cell. The device with the doped hole-extraction layer $(=0.43 \mathrm{wt} \%)$ showed a lowered fill factor (42.6) and the performance of the device was slightly degraded $(2.01 \%)$.

\section{Conclusion}

In conclusion, we have investigated the influence of alkali treatment with $\mathrm{NaOH}$ on the properties of PEDOT:PSS films. We have also examined the performance of organic solar cells with the un-doped and doped PEDOT:PSS layer. Results show that the acidity of PEDOT:PSS solution can be remarkably reduced by adding the $\mathrm{NaOH}$ solution with the optimal doping concentration $(\leq 0.43 \mathrm{wt} \%)$, while the $\mathrm{NaOH}$-doped PEDOT: PSS film shows an improved optical transmission and unchanged conductivity. However, compared with the pristine organic solar cell without adding $\mathrm{NaOH}$ to the whole-extraction layer, the $\mathrm{NaOH}$-doped organic solar cell shows a slightly degraded in the power conversion efficiency (from 2.12 to $2.01 \%$ ), which has been attributed to the decreased $\mathrm{V}_{\text {oc }}$ and fill factor of devices after the addition of $\mathrm{NaOH}$.

TABLE-1

PV PARAMETERS OF OPVs FOR NaOH DOPING

\begin{tabular}{ccccccc}
\hline Style & Structure & $\mathrm{pH}$ & $\mathrm{V}_{\mathrm{oc}}(\mathrm{V})$ & $\mathrm{I}_{\mathrm{sc}}\left(\mathrm{mA} / \mathrm{cm}^{2}\right)$ & Fill factor $(\%)$ & $\eta(\%)$ \\
\hline $\mathrm{A}$ & $\mathrm{ITO} / \mathrm{PEDOT}: \mathrm{PSS} / \mathrm{P}_{3} \mathrm{HT}: \mathrm{PCBM} / \mathrm{Al}$ & 1.51 & 0.56 & 8.82 & 43.0 & 2.12 \\
$\mathrm{~B}$ & $\mathrm{ITO} / \mathrm{NaOH}(0.43 \%)-\mathrm{PEDOT}: \mathrm{PSS} / \mathrm{P}_{3} \mathrm{HT}: \mathrm{PCBM} / \mathrm{Al}$ & 6.94 & 0.52 & 9.06 & 42.6 & 2.01 \\
$\mathrm{C}$ & $\mathrm{ITO} / \mathrm{NaOH}(0.47 \%)-\mathrm{PEDOT}: \mathrm{PSS} / \mathrm{P}_{3} \mathrm{HT}: \mathrm{PCBM} / \mathrm{Al}$ & 9.85 & 0.45 & 5.72 & 34.8 & 0.90 \\
\hline
\end{tabular}




\section{ACKNOWLEDGEMENTS}

Financial support from the program for Natural Science Foundation of Shandong Province (No. ZR2011EL033) is acknowledged. The Fund for Scientific Research Foundation from Shangdong University of Technology (No. 410010) is also gratefully acknowledged.

\section{REFERENCES}

1. G. Heywang and F. Jonas, Adv. Mater., 4, 116 (1992).

2. L. Groenendaal, F. Jonas, D. Freitag, H. Pielartzik and J.R. Reynolds, Adv. Mater, 12, 481 (2000).

3. S. Park, S.J. Tark and D. Kim, Curr. Appl. Phys., 11, 1299 (2011).

4. K.X. Steirer, M.O. Reese, B.L. Rupert, N. Kopidakis, D.C. Olson, R.T. Collins and D.S. Ginley, Sol. Energy Mater. Sol. Cells, 93, 447 (2009).

5. J. Li, J.C. Liu, C.J. Gao and G.H. Chen, Int. J. Photoenergy, 2011, 392832-1 (2011)

6. M.P. de Jong, L.J. van IJendoorn and M.J.A. de Voigt, Appl. Phys. Lett., 77, 2255 (2000).
7. K.W. Wong, H.L. Yip, Y. Luo, K.Y. Wong, W.M. Lau, K.H. Low, H.F. Chow, Z.Q. Gao, W.L. Yeung and C.C. Chang, Appl. Phys. Lett., 80, 2788 (2002).

8. T.P. Nguyen and S.A. De Vos, Appl Surf. Sci., 221, 330 (2004).

9. R.A. Hatton, N.P. Blanchard, L.W. Tan, G. Latini, F. Cacialli and S.R.P. Silva, Org. Electron., 10, 388 (2009).

10. M.D. Irwin, D.B. Buchholz, A.W. Hains, R.P.H. Chang and T.J. Marks, Proc. Natl. Acad. Sci. USA, 105, 2783 (2008).

11. T. Hasobe, S. Fukuzumi and P.V. Kamat, J. Phys. Chem. B, 110, 25477 (2006)

12. O.P. Dimitriev, Y.P. Piryatinski and A.A. Pud, J. Phys. Chem. B, 115, 1357 (2011).

13. S. Garreau, G. Louarn, J.P. Buisson, G. Froyer and S. Lefrant, Macromolecules, 32, 6807 (1999).

14. B.R. Saunders and M.L. Turner, Adv. Colloid. Interface Sci., 138, 1 (2008).

15. S.R. Forrest, MRS Bull., 30, 28 (2005).

16. F.L. Zhang, A. Gadisa, O. Inganäs, M. Svensson and M.R. Andersson, Appl. Phys. Lett., 84, 3906 (2004).

17. Y.W. Li, P.Y. Liu, L.T. Hou and B. Wu, Acta Phys. Sin., 59, 1248 (2010) (In Chinese).

18. J. Hwang, F. Amy and A. Kahn, Org. Electron, 7, 387 (2006). 